\title{
СОВРЕМЕННЫЕ ЛЕЧЕБНО-ДИАГНОСТИЧЕСКИЕ ОСОБЕННОСТИ ПЕРВИЧНЫХ ЦЕФАЛГИИ ПО НОВОЙ МЕЖДУНАРОДНОЙ КЛАССИФИКАЦИИ ГОЛОВНОЙ БОЛИ - ТРЕТЬЯ РЕДАКЦИЯ (2018)
}

В настоящее время головная боль (ГБ) является одной из наиболее распространенных жалоб на приеме невролога и входит в десятку частых причин нетрудоспособности в мире [1,2]. На глобальном уровне среди взрослого населения распространенность ГБ составляет около $50 \%$, при этом клинически приступы фиксировались не реже одного раза за последний год. В возрасте 18-65 лет ГБ отмечали до 75\% пациентов, среди которых более, чем у 30\% выявлены клинические критерии мигрени. От ГБ, продолжающейся 15 или более дней ежемесячно, страдает 1,7-4\% взрослого населения мира [3]. ГБ являются всемирной проблемой, поражающей население независимо от возраста, расы, уровня доходов и географического района. По данным исследования глобального бремени заболеваний выявлены основные причин нетрудоспособности в мире, указывая количество лет жизни (YLD - years lost due to disability), потерянных в следствие ухудшения здоровья без учета смертельных исходов. Установлено, что ГБ является четвертой причиной значительного социальноэкономического ущерба для общества, при этом по мнению Всемирной организации здравоохранения с 2013 года мигрень занимает шестую позицию. Согласно данным глобального бремени заболеваний (2015) мигрень признана третьей причиной инвалидности в мире как у мужчин, так и у женщин в возрасте до 50 лет $[1,2]$.

Впервые международная классификация ГБ (МКГБ) была предложена в 1988 году, второй пересмотр состоялся в 2004 году, краткая версия МКГБ - 3 (бета) предоставлена в 2013 году. На 18 Конгрессе Международного общества по изучению ГБ (International Headache Society - IHC2017, 7-10 сентября 2017 года, Ванкувер, Канада) председатель классификационного комитета, профессор неврологии Копенгагенского университета Джес Олесен представил финальную версию МКГБ - 3 (The International Classification of Headache Disorders, 3rd edition - ICHD-3) [4].
Каждая международная классификация ГБ сохранила градацию и состоит из трех разделов, посвященных первичным и вторичным ГБ, болевым краниальным невралгиям, лицевым болям и другим цефалгиям. Многочисленные эпидемиологические исследования, проведенные на протяжении последних десятилетий в большинстве стран мира, подтвердили значительное преобладание (90-95\%) первичных цефалгий над вторичными (5-10\%) [3, 4].

По данным эпидемиологических исследований S.D. Silberstein и соавт. (1993), O. Sjaastad и соавт. (2006), G.C. Manzoni и соавт., (2010), X. Wang и соавт. (2015) получены неоднородные результаты в связи с разной методологией их получения. Частота встречаемости ГБ в России, по мнению разных авторов, варьирует от $25 \%$ до $93 \%$, за рубежом - от 7,3\% до 93\%, но в большинстве публикаций достигает 50-60\% [5]. Сопоставимые эпидемиологические показатели для мигрени имеют вариабельность частоты встречаемости от $2,6 \%$ до $27,9 \%$, в большинстве публикаций $-10-15 \%$. По сведениям из различных отечественных и зарубежных источников ГБ напряжения встречается у 1,8-80\% населения, в большинстве публикаций - у 40-50\% [3,5].

По данным датского профессора неврологии Ригмор Йенсен в 2017 году определена частота форм ГБ по обращаемости пациентов в специализированный центр ГБ, не показывая популяцию Дании в целом. Установлено, что первое место занимает мигрень (41\%), второе - и головная боль напряжения (25\%). Выявляемость абузусной ГБ занимает третье место и формируется в результате неадекватного лечения ПГБ, таких как мигрень и ГБН. В отношении идиопатической внутричерепной гипертензии (11\%), невралгии тройничного нерва (4\%) и других ГБ

(c) Ю.И. Коценко, Е.А. Статинова, А.М. Бубликова,

О.Л. Максименко, 2020

(c) Университетская Клиника, 2020 
(5\%), в том числе цервикогенных, то их диагнозы выставляются повсеместно за счет гипердиагностики и встречаются значительно реже, чем принято о них думать [6]. В связи с частыми «ложными» диагнозами цефалгий, где преимущество остается за вторичными болями, и назначением неэффективной терапии, возникает необходимость в применении более современных лечебно-диагностических мероприятий по ГБ.

\section{ЦЕЛЬРАБОТЫ}

Изучить и проанализировать обновленную версию МКГБ-3 2018 года и определить ведущие лечебно-диагностические направления с учетом современной классификации.

Современная международная классификация претерпела изменения (МКГБ-3, 2018). Произошли изменения в разделе мигрени с аурой в рамках диагностики с транзиторной ишемической атакой (ТИА), кроме того хроническая мигрень включена в основные диагнозы классификации. Новые диагностические критерий, включенные в раздел мигрень с аурой, что позволяет лучше отличить ее от ТИА. К основным критериям относятся: достоверный диагноз ауры или схожие проявления, длительные или кратковременные приступы с аурой, возникновение впервые после 40 лет с наличием исключительно отрицательных симптомов (например, гемианопсия) [3].

Согласно Международной классификации болезней 11-го пересмотра (2018) ГБ относится к разделу 08 Болезни нервной системы. Таком образом ГБ классифицируется, как 8А80 мигрень: 8А80.0 мигрень без ауры, 8А80.1 мигрень с аурой (8А80.10 гемиплегическая мигрень, 8А80.1Y другая мигрень с аурой, уточненная, 8A80.1Z мигрень с аурой, неуточненная); 8А80.2 хроническая мигрень, 8А80.4 синдром циклической рвоты, 8А80.Y другая уточненная мигрень, 8A80.Z мигрень неуточненная. Выделяют 8A80.3 осложнения, связанные с мигренью (8А80.30 мигренозный статус, 8А80.3Y другие уточненные осложнения, связанные с мигренью). В том числе к первичным цефалгиям относятся 8А81 головная боль напряжения (ГБН) (8А81.0 редкие эпизодические ГБН, 8А81.1 частые эпизодические ГБН, 8А81.2 хроническая ГБН, 8А81.Y другие ГБН уточненные, 8A81.Z ГБН, неуточненные), 8А82 тригеминальные вегетативные цефалгии (исключены 8С00.20 невралгия тригеминальная и DAOF.0 синдром горения), 8A83 другие первичные ГБ. В МКБ-11 (2018) также выделяют 8А84 вторичные ГБ (8А84.0 острая ГБ, связанная с травмой головы, 8A84.1 упорная ГБ, связанная с травмой головы, 8A84.Y другая уточненная вторичная ГБ, 8A84.Z вторичная ГБ неу- точненная), 8А85 невралгии черепно-мозговых нервов или другие боли в лице, 8 А8Y другие ГБ, уточненные, 8A8Z ГБ, неуточненные [5].

Пересмотрены также диагностические критерии других первичных цефалгий, возникающих при кашле, физических нагрузках, связанных с сексуальной активностью, громоподобной, колющей, нуммулярной и гипнической болью. Среди других первичных цефалгий в возрасте 40 лет встречается кашлевая ГБ, которая начинается с 2 атак и прослеживается тесная положительная корреляция между частотой кашля и тяжестью ГБ. Что касается нуммулярного типа цефалгия имеет непрерывную или прерывистую характеристику локализованную в области кожи головы, резко очерченную с фиксированным размером и округлой эллиптической формой до 6 мм в диаметре. При физическом напряжении возникают 2 атаки пульсирующей ГБ, возникающей во время или сразу после напряженных физических упражнений. Коитальную ГБ инициирует сексуальная активность до 2 атак от 1 минуты до 72 часов, усиленной интенсивности с повышенным сексуальным волнением и/или только резкой взрывной интенсивности. Громоподобная ГБ - это сильная ГБ с резким началом максимально до 1 минуты, но в совокупности не более 5 минут. Внешний холодный стимул к голове, вдыхание воздуха и проглатывание холодной пищи инициирует первичную ГБ на холодовые стимулы, где временный приступ регрессирует в течение 30 минут после прекращения стимулирования. При этом ГБ развивается остро с одной стороны до 2 атак во фронтальной или ретроорбительной областях [3].

Цефалгия от внешнего сдавления развивается в течение часа при постоянной внешней компрессии лба или волосистой части головы, максимально в месте внешнего сдавления до 2 атак и сохраняется менее часа после внешних воздействий. Колющая ГБ имеет самопроизвольный характер длительностью до нескольких секунд с нерегулярной частотой от одной до нескольких атак в день при отсутствии черепных вегетативных симптомов. В исследовании отмечено, что в 80\% случаев атака длиться до 3 секунд, редко 10-120 секунд, 70\% случаев выявлена связь с экстратригеминальными областями и у 1/3 больных имело место фиксированное местоположение ГБ. К клиническим критериям гипнической ГБ относятся повторяющиеся приступы во время сна, которые вызывают пробуждение. При этом частота приступов 10 дней в месяц, где период наблюдения составил более 3 месяцев и длительностью от 15 минут до 4 часов после пробуждения с отсутствием краниальных вегетативных симптомов или беспокойства. По 
данным исследования у $1 / 5$ больных 50 лет характер ГБ имел выраженные проявления и у $2 / 3$ пациентов боль носила двустороннюю локализацию. Новая ежедневная (изначально) персистирующая ГБ (NDPH) двустороння и/или давящая, сжимающая (непульсирующая) легкой или умеренной интенсивности без влияния физических нагрузок и длиться постоянно в течение более 3 месяцев с непрерывностью в течение суток или последующей хронизацией в течение 3 дней в сочетании с отсутствием умеренной или сильной тошноты и рвоты и не более одного симптома (фотофобия, фонофобия, легкая тошнота). По данным МКГБ-3 (2018) разделы, касающиеся ГБН и тригеминальных вегетативных цефалгий, существенно не изменились [3].

На сегодняшний день патогенез первичных цефалгий изучен недостаточно. Однако, некоторые исследования представляют теории развития мигрени, которые имеют право на существование. К основным наиболее изученным теориям развития мигрени относят сосудистую, тромбоцитарную, серотонинергическую, нейрогенную и нейроваскулятрную (тригеминальноваскулярную) теории $[7,8]$.

Традиционно мигрень рассматривается как внезапно развивающаяся генерализованная декомпенсация вазомоторной регуляции и проявляется лабильностью тонуса мозговых и периферических сосудов, которые сопровождаются регионарными изменениями мозгового кровотока. Вместе с тем приступ ГБ является следствием избыточной вазодилатации интракраниальных (оболочечных) и экстракраниальных артерий, а периодическое растяжение сосудистой стенки приводит к активации болевых рецепторов и придает ГБ пульсирующий характер. Аура при мигрени обусловлена локальным вазоспазмом с развитием локальной ишемии мозга и появлением очаговых неврологических симптомов (скотомы, гемианопсии, головокружение и др.). При церебральной ангиографии нередко диагностируют сосудистые мальформации. В 60-е годы в Германии исследователем Г. Хейком была предложена теория шунта, при которой кровь стремиться пройти из артерии непосредственно в вену через артериовенозный шунт, минуя внутричерепные капилляры, с возникновением ГБ и ишемии мозга [7].

Нейрогенная теория определяет мигрень как заболевание с первичной нейрогенной церебральной дисфункцией. Также во время приступа возникновение сосудистых изменений носят вторичный характер. Теория редко изучается без учета сосудистых изменений. По данным исследователей, основой нейрогенной теории является наследственная дегенерация некото- рых нейронов, участвующих в иннервации сосудистых стенок. В результате нарушения синтетической способности в сосудистой стенке происходит изменения процессов, что сказывается на состоянии артерий. Возникает сложность выполнения исследования нервов, которые иннервируют сосуды для получения полного представления об их влиянии на развитие мигренозного приступа [8].

Тромбоцитарная теория развивается в следствие изначальной первичной патологии тромбоцитов, которые при определенных условиях адгезируются, в результате резко выделяется значительное количество нейротрансмиттера 5-гидроокситриптамина (5-НТ) (серотонин). Одномоментно усиливается выработка гистамина тучными клеткам. В последующем серотонин и гистамин начинают выводиться почками с уменьшением их уровня в организме, что приводит к вазодилятации, снижению их тонуса с развитием отека периваскулярного пространства, снижению болевого порога стенок артерий и возникновением боли $[9,11]$.

На сегодняшний день выделяют серотонинергическую теорию, при которой происходит резкое снижение нейротрансмиттера серотонина в тромбоцитах до 30-40\% с усилением экскреции почками продуктов его метаболизма серотонина. Нейротрансмиттер серотонин оказывает широкий спектр действия в организме вследствие наличия многочисленных рецепторов, расположенных в кровеносных сосудах всего организма, в том числе и головного мозга. Среди значительного количества серотонинергических рецепторов в патогенезе мигрени важную роль играют 5-НT1, 5-НТ2 и 5-НТ3 рецепторы. 5-НТ1 рецепторы относятся к ингибирующим рецепторам и подразделяются на 5-HT1A, 5-HT1B, 5-HT1D и 5-HT1F, где 5-НT1А ослабляют вегетативные (тошнота, рвота) и психоэмоциональные (тревога, депрессия) симптомы, сопровождающие приступ мигрени, 5-НТ1В являются постсинаптическими рецепторами кровеносных сосудов, преимущественно интракраниальных, 5-HT1D - пресинаптические рецепторы в окончаниях тройничного нерва. Рецепторы 5-НТ2В/С эндотелия мозговых сосудов активируют липоксигеназный и циклоксигеназный механизмы воспаления, повышают выделение радикалов окиси азота (NO'). NO' освобождает пептиды, ответственные за развитие нейрогенного воспаления (цефалгия является побочным эффектом нитроглицерина - источника NO). Peцепторы 5-HT3 находятся на чувствительных окончаниях нейронов, участвующих в восприятии боли [7, 9-11]. 
Ведущей теорией патогенеза развития мигрени исследователи считают тригеминальноваскулярную (М. Moskowitz и соавт. 1989, К.M. Welch 2003), когда нарушена нормальная взаимосвязь между церебральными сосудами и тройничным нервом, находящиеся под контролем срединно-стволовых структур головного мозга. При спонтанном приступе мигрени происходит активация стволовых структур мозга, расположенных возле сильвиева водопровода, в области синего пятна и ретикулярной формации, которые являются своеобразным генератором приступа мигрени. Ключевая роль отводится нейрогенному асептическому воспалению вследствие антидромной активации тригеминальноваскулярной системы и выделения из терминалей чувствительных нервных волокон в стенке сосудов вазоактивных нейропептидов (гистамин, простогландины, субстанция Р, нейрокинин А, белок, связанный с геном кальцитонина - calcitoningenerelated peptide, CGRP) [12]. В результате нейрогенного воспаления возникает расширение сосудов, увеличение проницаемости сосудистой стенки для белков плазмы и форменных элементов крови, отек сосудистой стенки и прилегающих участков твердой мозговой оболочки, дегрануляцию тучных клеток, агрегацию тромбоцитов. Асептическое нейрогенное воспаление активирует ноцицептивные терминали афферентных чувствительных волокон тройничного нерва и передается в его чувствительное ядро, расположенное в стволе, в задние рога спинного мозга на уровне первого и второго сегментов, в зрительный бугор и корковые отделы чувствительного анализатора, что в последующем приводит к формированию болевых ощущений. Также в каудальной пластинке тригеминального ядра обнаружено повышение уровня специфического иммунореактивного нейропептида c-fos, носителя патологической «болевой» памяти, участвующего в медиации болевых ощущений и также влияющего на активацию системы тройничного нерва [7, 10, 12].

В последнее десятилетие активно изучается роль окиси азота (NO) в патофизиологии мигрени. В экспериментах показано, что NO, образующаяся в эндотелии сосудов является мощным дилататором церебральных сосудов, а также содержится и в периваскулярных нервных сплетениях, окружающих мозговые сосуды. Следовательно, NO, как и CGRP, также представляет собой медиатор нейрогенного воспаления: вопервых, активирует окончания тригеминальных волокон, что приводит к высвобождению болевых нейропептидов и, во-вторых, оказывает непосредственно вазодилятаторное воздействие. Также показано, что NO играет важную роль в центральном проведении болевых стимулов и гипералгезии [7, 11, 13].

Немаловажное значение в развитие мигрени играет генетика. Неоднократно исследователи отмечали наследственный характер развития мигрени. При этом показывали увеличение риска развития мигрени до 70\% при наличии у индивида положительного семейного анамнеза. Установлены генетические механизмы мигрени, где семейная гемиплегическая мигрень (СГМ) является генетически гетерогенным заболеванием, при этом каждому фенотипическому варианту соответствуют вариации определенных мутаций генов. Однако, на данном этапе мнения исследователей отличаются. СГМ 1 типа имеет миссенс-мутации в гене CACNA1A (5075\% семей); СГМ 2 типа - в основном делеции и сдвиг рамки считывания в гене АТР1А2 (20\%30\% случаев); мутация в гене АТР1А2 приводит к loss-of-function эффекту (нарушению регуляции транспорта ионов $\mathrm{Na}+$ и $\mathrm{K}+$ в клетке, обратному захвату нейромедиаторов из синаптической щели и приводит к гипервозбудимости нейронов). СГМ 3 типа развивается в следствие мутации в гене SCN1A на 2q24, кодирующий $\alpha 1$ субъединицу нейронального Nav1·1 потенциалзависимого натриевого канала, который отвечает за генерацию и проведение потенциала действия. Мутация в гене SCN1A приводит к более быстрому восстановлению мембранного потенциала после деполяризации $\mathrm{Na-каналов} \mathrm{нейро-}$ нов Nav1·1 и gain-of-function эффекту (избыточному выбросу нейромедиаторов и гипервозбудимости нейронов). СГМ 4 типа вызвана мутацией в гене CACNA1E в 1q25-q31; СГМ 5 типа мутациями в других генах (SLC1A3). Оценить генетику самых распространенных форм мигрени довольно трудно, поскольку в настоящее время не определены маркеры этой болезни. За последнее десятилетие геномный скрининг позволил идентифицировать хромосомные локусы, обнаруживающие сцепление с мигренью (1q31, 4q21, 4q24, 6p12.2-p21.1, 10q22-q23, 11q24, 14q21.2-q22.3, 15q11- q13,19p13, Хq25-q28), и локусную гетерогенность. Выявлен наиболее часто встречаемый аутосомный локус на хромосоме $4 q$ [14-16].

Активно применяется метод ассоциативного анализа, который основан на выборе геновкандидатов, имеющих полиморфизм и относящихся к одной из физиологических или клеточных систем, нарушение которых могут потенцировать развитие заболевания. Геныкандидаты сгруппированы в четыре функциональных семейства генов. Первую группу образовали гены, участвующие в работе нервной системы (ионные каналы; субъединицы $\mathrm{Na}+$ / 
К+-АТФазы; молекулы, участвующие в синтезе, высвобождении и связывании нейропептидов (CGRP или нейтротрансмиттеров: глутамата, ГАМК, дофамина, серотонина), относящихся к нейрональному возбуждению и/или ноцицепции). Вторую группу вошли васкулярные гены (ангиотензин превращающий фермент; 5-10метилентетрагидрофолат редуктаза (MTHFR), как ключевой компонент реметилирования гомоцистеина в метионин; NOTCH3, кодирующий трансмембранный рецептор, регулирующий развитие сосудов, дифференцировку в процессе эмбриогенеза и способствует целостности сосудов у взрослых. К другим эндотелиальным генам относят оцениваемые гены и ассоциацией их с мигренью, которые кодируют эндотелин-1 (EDN1), рецепторы эндотелина типа A и B (EDNRA и EDNRB), индуцибельную NO-синтазу (NOS2), эндотелиальную NO-синтазу (NOS3), и сосудистый эндотелиальный фактор роста (VEGF). Многие васкулярные гены, ассоциированные с мигренью, представляют риск развития цереброваскулярных и кардиоваскулярных заболеваний [14-16].

Третья группа представляет собой гены, контролирующие метаболизм эстрогена и прогестрерона и теоретически могут быть ассоциированы с мигренью, однако, результаты исследований генетической ассоциации довольно противоречивы. Четвертая группа выделяет гены, связанные с нейрогенным воспалением на фоне распространяющейся корковой депрессии, с последующей активацией тучных клеток и макрофагов, высвобождением провоспалительных цитокинов и конечной сенситизации менингеальных ноцицептивных нервных окончаний $[15,16]$.

Немаловажную роль в диагностике цефалгий играют опросники. К основным относят визуально-аналоговую шкалу боли (ВАШ), MIDAS, HIT-6, HART, LDQ. Опросник ВАШ наглядно демонстрирует выраженность цефалгии, где боль с лекарственно-индуцированной ГБ соответствует 2-3 баллам, при ГБН - 5 баллов, а при кластерной ГБ симптомы цефалгии настолько выражены, что больным «не хватает» шкалы [17].

Для оценки степени дезадаптации пациента при мигрени повсеместно используют опросник «MIDAS» («Migraine Disability Assessment Questionnaire») (R.Lipton, W.Stewart). В данном опроснике ГБ непрерывной длительностью 3 месяца полученные результаты показывают влияние мигрени на повседневную деятельность, в том числе активный отдых и участие в семейных и общественных мероприятиях. Определяется тяжесть ГБ в баллах, где они объединяются в соотвествтующую степень: I (0-5 баллов) спепень - малая интенсивность ГБ, отсутствие или минимальное снижение повседневной активности, II (6-10 баллов) - умеренная / выраженная ГБ, незначительное ограничение повседневной активности, III (11-20 баллов) - сильная ГБ, выраженное ограничение повседневной активности, IV (более 21 балла) - сильная ГБ, значительное снижение повседневной активности. оценка влияния ГБ применяется короткий опросник HIT-6 (Headache Impact Test-6), который помогает пациенту описать свои ощущения и степень нарушения их повседневной активности. Лечебная тактика ГБ не всегда может быть эффективна, поэтому для оценки ответа на лечение ГБ разработана шкала HALT (Headache-Attributed Lost Time - временя, потерянное из-за ГБ). Также используется Лидский опросник зависимости от обезболиващих препаратов (LDQ - Leeds Dependence Questionaire) для диагностики лекарственно-индуцированной ГБ $[1,17]$.

Впервые в 2008 году презентован диагностический алгоритм ГБ, который несколько модернизирован с учетом МКГБ-3 (2018). Данный алгоритм позволяет провести дифференциальный диагноз первичных и вторичных цефалгий, основываясь на клинических критериях, предоставленных с МКГБ-3. Структура алгоритма представляет собой клиническое интервью с качественным сбором жалоб, анамнеза, наследственности, тщательного объективного осмотра и клинико-неврологических данных. В результате полученных ответов, типичной клинической картине и удовлетворительных данных осмотра диагноз первичных цефалгий правомочен. Однако, если имеет место нетипичная клиника, наличие «красных флагов» или «сигналов опасности» начначаются дополнительные методы обследования, подтверждающие вторичный характер цефалгии [3, 7].

$\mathrm{K}$ «красным флагам» относят новую ГБ (впервые возникшую; изменившую свой обычный паттерн); «громоподобную» со стремительным началом; ГБ с подострым началом без ремиссии с постоянным прогрессированием; ГБ с дебютом после 50 лет при наличии в анамнезе онкологических заболеваний, иммунодефицита, эндокринных нарушений в сочетании с неврологическим дефицитом (нарушение сознания и память, дискоординация, парезы и параличи, поражение черепных нервов, изменение рефлексов, менингеальные симптомы, зрительные расстройства, эпилептические припадки); признаки внутричерепной гипертензии; наличие других патологических симптомов (лихорадка, потеря веса, длительный кашель, лимфоаденопатия, насморк или затруднённое носовое 
дыхание); резистентность к стандартному лечению; сверхвысокое АД (диастолическое выше 120 мм рт.ст) [3].

Назначение дополнительных методов исследования при ГБ показано при подозрении на вторичный (симптоматический) характер: сомнения в вероятном клиническом диагнозе первичной ГБ (нетипичные жалобы или течение ГБ, выявление не всех признаков первичных ГБ), наличие более одного из «сигналов опасности» и выявление диагностических признаков вторичной ГБ (ГБ непосредственно связана с началом или обострением основного заболевания (причина ГБ); наличие клинических симптомов, данных лабораторных и инструментальных исследований, подтверждающих основное заболевание; исчезновени ГБ во время ремиссии или при успешном лечении основного заболевания) $[3,4,7]$.

Для проведения нейровизуализационных исследований при ГБ необходимо наличие одного из следующих критериев: персистирующая мигренозная ГБ длительностью менее 6 мес, без эффекта; мигренозная ГБ с органическими неврологическими признаками (отеком диска зрительного нерва, нистагмом, парезами, атаксией, персистирующая ГБ без семейного анамнеза мигрени); персистирующая ГБ, сочетающаяся с эпизодами нарушения сознания, дезориентацией или рвотой; начало мигрени в возрасте старше 50 лет; мигренозная ГБ у ребенка, повторно пробуждающая его или возникающая сразу после пробуждения; семейная предрасположенность к заболеваниям центральной нервной системы или наличие клинико-лабораторных отклонений, которые указывают на заболевание, также нетипичная, пролонгированная или персистирующая аура $[4,7]$.

Оптимизация лечения для конкретных больных с первичными цефалгиями остается сложной задачей. В настоящее время тактика лечения индивидуализирована. Согласно рекомендациям протокола (American Headache Society, 2018) в лечении острой мигрени необходимо использовать доказательное лечение, которое следует начинать при первых признаках ГБ, применять инъекционные препараты, если приступы связаны с тошнотой / рвотой или пациент испытывает затруднения при глотании, контролировать переносимость и безопасность лечения, рассматривать возможность применяемых самостоятельно мер неотложной терапии, а также избегать чрезмерного употребления средств неотложной лекарственной терапии [3, 4].

По данным отечественных и зарубежных исследований за последнее десятилетие разработан ряд направлений специфической терапии: агонисты серотониновых рецепторов, джепанты, моноклональные антитела (PROMISE I, II), антагонисты глутамата, антагонисты ваниллоидных рецепторов, ингибиторы NO-синтазы. B небольшом когортном исследовании высокоселективный ингибитор NO-синтетазы GW274150 показал обезболивающее действие, однако эффективность не была подтверждена в рандомизированном двойном слепом плацебоконтролируемом исследовании $[13,18]$.

Большинство из специфических препаратов, применяемых в лечении острой мигрени, являются 5-HT1B/5-HT1D агонисты. Специфические 5-HT1F агонисты проходят клинические исследования. Рецепторы 5-HT1D являются пресинаптическими в окончаниях тройничного нерва и их стимуляция вызывает уменьшение выброса вазоактивных полипептидов (CGRP и субстанция Р), снижая степень нейрогенного воспаления. 5-НТ2 агонисты имеют значение для многих превентивных медикаментов, таких как метисергид и пропранолол. Антагонист 5-НT3 рецепторов метоклопрамид полезен в лечении ассоциированной с мигренью рвоты. Тошнота и рвота при мигрени отчасти возникают вследствие стимуляции этих рецепторов, которые находятся преимущественно в центрах тошноты и рвоты нижних отделов ствола мозга [19].

B лечения мигрени разработаны антагонисты CGPR: низкомолекулярные ингибиторы (джепанты) и моноклональные антитела против CGPR-рецептора. B 2015 году компания ALLERGAN приобрела у Merck\&Co. права на низкомолекулярные антагонисты CGRP для перорального применения: MK-1602 (для купирования приступов) и МК-8031 (для длительной профилактики мигрени). МК-1602 продвинулся в III фазу исследования. Параллельно в июне 2015 году появляется конкурентный класс CGRP-антагонистов - моноклональные антитела против лигандов и рецепторов этой системы («Илай Лилли» Eli Lilly с препаратом LY2951742, «Олдер байофармасьютикалс» Alder Biopharmaceuticals c ALD-403 и TEVA с TEV-48125). В 2018 году компания ALLERGAN продемонстрировали эффективность и статистическую достоверность клинического исследования ACHIEVE I (UBR-MD-01) экспериментального препарата уброгепант (низкомелекулярный пероральный ингибитор активности нейропептида, кодируемый CGRP) для купирования умеренных и тяжелых приступов мигрени [20, 21]. Данный вариант лечения джепантами не приводит к вазоконстрикции, но играет особую роль у пациентов с кардиоваскулярными противопоказаниями к применению триптанов [22]. 
В настоящее время также синтезированы ольцеджепант (BIBN4096BS, вводится внутривенно) и телкаджепант (МК-0974, перорально). Ольцеджепант был эффективен при купировании мигренозного приступа с хорошей переносимостью во II фазе клинических исследований, а телкаджепант - в III фазе. При этом в многоцентровом рандомизированном плацебоконтролируемом исследовании телкаджепант (300 мг) был более эффективен, чем золмитриптан (5 мг) и плацебо. Но телкаджепант не может использоваться с профилактической целью для лечения мигрени, т. к. повышает уровень печеночных трансаминаз [23-25].

Также AMGEN / Novartis опубликовал предварительные результаты второй части исследования STRIVE (Study to Evaluate the Efficacy and Safety of Erenumab in Migraine Prevention). Проанализирована эффективность AMG 334 (Erenumab / Aimovig ${ }^{\mathrm{TM}}$ ) после 52 недель приема (13 ежемесячных инъекций). В результате у $62 \%$ пациентов количество дней с мигренью уменьшилось вдвое по сравнению с началом исследования, у 38\% - на три четверти, у 20\% - приступов к концу 52 недель мигрени больше не отмечалось. В среднем у испытуемых при получении лечения в течение 52 недель количество дней с мигренью уменьшилось на 4,9 дней в месяц по сравнению с началом исследования. Статистических данных по побочным эффектам пока нет. При этом серьезные побочные эффекты (SAE) были отмечены у 13 пациентов, где один из них связан с препаратом, но характер неизвестен. В 2017 году на 17 Конгрессе International Headache Society в Валенсии AMGEN представило моноклональные антитела AMG 334 и поделилась результатами плацебо-контролируемого исследования II фазы у пациентов с мигренью. Исследование NCT01952574 сравнило AMG 334 против плацебо в качестве меры профилактики у больных с частотой приступов от 4 до 14 в месяц. Эффективность AMG 334 и плацебо оценивалась по стандартным критериям: уменьшение количества дней в месяц, в которые у пациента была мигрень, сравнение удельного веса пациентов в группах, у которых количество дней с мигренью уменьшилось вдвое и уменьшение количества дней в месяц, в которые пациентам пришлось применять лекарства для купирования приступов [26-28].

В начале терапии приступов ГБ рекомендован таблетированный прием минимальной дозы с последующим титрованием до целевой (максимально эффективной) дозы. Прежде чем определить недостаточную эффективность препарата у пациентов с хронической мигренью, следует использовать профилактическое лече- ние в течение минимум 8 недель в целевой терапевтической дозе. Пациентам с частичным ответом следует пояснять, что накопление препарата достигается от полугода до года непрерывного применения [29].

Долгосрочная приверженность пероральному профилактическому лечению является низкой, в основном из-за неоптимальной эффективности и плохой переносимости. Успех профилактического лечения определяется как 50\% уменьшение количества дней с цефалгией; значительное уменьшение продолжительности и снижение тяжести приступа, определяемое пациентом; улучшенный ответ на медикаментозное лечение острого приступа; снижение инвалидности, связанной с мигренью; улучшение функционирования в важных сферах жизни; улучшение качества жизни и снижение психологического стресса из-за мигрени [29-31].

С учетом уровня эффективности и классификации доказательств Американской академии неврологии (American Academy of Neurology - AAN) следующие пероральные методы лечения доказали свою эффективность и должны быть предложены для профилактики мигрени. K первой группе препаратов для профилактики с установленной эффективностью (>2 исследований класса I) относятся антиконвульсанты (дивалпроекс натрия, вальпроат натрия, топирамат), блокаторы бета-адренорецепторов (метопролол, пропранолол, тимолол), фроватриптан (для кратковременного профилактического лечения менструальной мигрени) и онаботулотоксин А. Вероятная эффективность (1 исследование класса I или 2 исследования класса II) выявлена при применении антидепрессантов (амитриптилин, венлафаксин); блокаторов бета-адренорецепторов (атенолол, надолол), блокаторов ангиотензиновых рецепторов (кандесартан). Возможная эффективность (1 исследование класса II) определена при использовании ингибитора ангиотензинпревращающего фермента пролонгированного действия (лизиноприл); альфа-2-адреномиметиков (клонидин, гуанфацин); антиконвульсанта (карбамазепин); блокаторов бета-адренорецепторов (небиволол, пиндолол); антигистаминных средств первого поколения с дополнительными антихолинергическими, антисеротонинергическими и местными анестезирующими свойствами (ципрогептадин) и блокаторами ангиотензиновых рецепторов (кандесартан) [22, 32, 33].

В 2018 году управление по контролю за продуктами и лекарственными препаратами США (FDA) одобрило применение моноклональных антител на CGRP-лиганд [33, 34]. В настоящее время для инъекционной профилактиче- 
ской терапии мигрени рекомендованы онаботулинотоксин А (одобрен для хронической мигрени) [35] и 3 моноклональных антитела (одобрены для эпизодической и хронической мигрени), где фреманезумаб (fremanezumab, «Ajovy», TEV48215 or LBR-101) [36-39], галканезумаб (galcanezumab «Emgality», LY2951742) [40, 41] нацелены на пептид, связанный с CGRP; эренумаб (erenumab, «Aimoving») - на рецептор CGRP [41-43]. Однако, принципы профилактической терапии для пероральных профилактических средств обычно применяются к инъекционным профилактическим средствам, где нет необходимости в постепенном повышении дозы: онаботулинотоксина А в оптимальной (начальной) дозе 155 ЕД; эренумаб в 2 дозах (70 мг и 140 мг) может использоваться в качестве начальной; фреманезумаб в дозах 225 и 675 мг назначается для ежемесячных и ежеквартальных схем дозирования, соответственно; галканезумаб предоставляется в дозе 120 мг, предназначенной для ежемесячного применения после начальной нагрузочной дозы 240 мг [44-46].

Для назначения моноклональных антител к пептиду, связанному с CGRP и к его рецептору, должна быть диагностирована мигрень с аурой или без нее по МКГБ-3 (4-7 или 8-14 приступов ГБ в месяц) у пациентов старше 18 лет с невозможностью переносить (из-за побочных эффектов) или неадекватным ответом на 6-недельное применение минимум 2 из следующих препаратов (топирамат; дивалпроекс натрия/вальпроат натрия; блокаторы бета-адренорецепторов: метопролол, пропранолол, тимолол, атенолол, надолол; трициклические антидепрессанты: амитриптилин, нортриптилин; ингибиторы обратного захвата серотонина-норадреналина: венлафаксин, дулоксетин; другие методы лечения уровня установленной эффективности или вероятной эффективности в соответствии с рекомендациями AAN). А также с умеренной инвалидностью (по Шкале оценки влияния мигрени на повседневную активность (MIDAS) >11 баллов, по Индексу влияния ГБ (НІТ-6) >50 баллов) [47, 48]. В том числе если диагностирована хроническая мигрень по МКГБ-3 с неспособностью переносить (из-за побочных эффектов) или неадекватный ответ на 6-недельное применение 2 из препаратов, описанных выше, или неадекватный ответ на минимум 2 ежеквартальные инъекции (6 мес.) онаботулинотоксина А. Первоначальный эффект оценивается после 3 мес. для ежемесячного лечения и 2 циклов лечения (6 мес.) для ежеквартального лечения пациента $[33,46]$.

Для продолжения приема моноклональных антител необходимо учитывать уменьшение среднемесячного количества дней с ГБ $\geqslant 50 \%$ по сравнению с исходным уровнем перед лечением (ведение дневника или записи врача), клинически значимое улучшение любого из следующих подтвержденных критериев исхода, специфических для пациентов с мигренью: MIDAS (снижение на $\geqslant 5$ баллов, если базовый балл составляет 11-20 или снижение на $\geqslant 30 \%$ при базовых оценках >20); дневник воздействия мигрени на функциональный статус (migraine physical function impact diary - MPFID) (снижение на $\geqslant 5$ баллов); НІТ-6 (снижение $\geqslant 5$ баллов) $[41,42,46]$.

В клиническом исследовании изучалось влияние глутамата, который модулирует активность 5-HT1B/5-HT1D/5-HT1F-рецепторов, на активацию тригемино-васкулярной системы, развитие центральной сенситизации и распространяющейся корковой депрессии в патогенезе мигрени. В 2017 году исследовали антагонисты $\alpha$-амино3-гидрокси-5-метил-4-изоазолепропионовых (AMPA) и каинатных рецепторов LY-293558 (тезампанел), которые эффективнее плацебо и сопоставимы по эффективности с суматриптаном по всем основным показателям. При использовании модели нейрогенной вазодилатации активация ионотропных рецепторов (iGluR5) подавляла расширение сосудов твердой мозговой оболочки. В тот же время антагонист каинатных рецепторов оказывал центральное антиноцицептивное действие. При этом антагонист глутаматных рецепторов, BGG492, переходит во II фазу клинических исследований [47-49].

Ваниллоидные рецепторы (TRPV1, transient receptors potential vanilloid) экспрессируются ноцирецепторами, активируются неспецифическими стимулами, способными вызвать боль, даже под действием специфических лигандов (ваниллоидов). Эндогенныеми лигандам ваниллоидных рецепторов являются анандамид и $\mathrm{N}$-арахидоноилдофамин. Ваниллоидные рецепторы локализуются на нервных окончаниях афферентных немиелинизированных С-волокон, расположенных субэпителиально. К антагонистам ваниллоидных рецепторов относят капсаицин (вводят внутрипузырно 100 мг на 30 мин), ресиниферотоксин. [50].

Оценка эффективности неотложной помощи, основана на экспертном обзоре по результатам контролируемых исследований, проведенном в 2018 году Американским обществом по борьбе с головной болью (American Headache Society) и указаны лекарственные средств для терапии головной боли с установленной и вероятной эффективностями: триптан против эрготаминов и дигидроэрготаминов; производные эрготамина против эффективности нестероидных противовоспалительных препаратов (НПВП) (кетопрофен, кеторолак внутривенно или внутри- 
мышечно, флурбипрофен); НПВП (ацетилсалициловая кислота, диклофенак, ибупрофен, напроксен) против сернокислой магнезии (MgSO4) внутривенно; опиоиды (буторфанол) против изометептен; комбинированные препараты против комбинаций (кодеин + ацетаминофен, трамадол + ацетаминофен), а также противорвотные средства (прохлорперазин, прометазин, дроперидол, хлорпромазин, метоклопрамид). Рекомендуется парентеральный путь введения пациентам, у которых приступы связаны с сильной тошнотой и рвотой или наличие дискомфорта при глотании перорально вводимых лекарств (суматриптан 3-6 мг подкожно; интраназальные и ингаляционные порошковые препараты; кеторолак в интраназальных и внутримышечных препаратах, дигидроэрготамин подкожно и интраназальный спрей; дигидроэрготамин внутривенно и противорвотное средство следует применять при особенно рефрактерной головной боли; хлорперазиновые суппозитории (при ГБ и тошноте) продемонстрировали свою эффективность [51, 52].

\section{В Ы В О д Ы}

Подавляющее большинство пациентов (7090\%), обращающихся с жалобой на ГБ к терапевтам и неврологам имеют первичную ГБ, где чаще встречаются: мигрень, ГБН, лекарственноиндуцированная ГБ (абузусная). Диагностика первичной ГБ является исключительно клини- ческой, дополнительные исследования не показаны, не информативны и проводятся при наличии показаний (подозрение на вторичную ГБ).

На сегодняшний день существуют, активно разрабатываются и внедряются новые подходы к диагностике и лечению первичных цефалгий, которые помогут практикующим специалистам в ведении категории пациентов с тяжелыми формами. Установлено, что в основе развития мигрени, одной из форм первичных ГБ, лежит сложный патогенетический комплекс взаимоотношений, связанных с гипервозбудимостью ноцицептивных (болевых) нейронов. При этом возникает особое функциональное состояние образований тройничного комплекса, иннервирующего крупные артерии головного мозга и твердой мозговой оболочки, со снижением активности антиноцицептивной системы. Учитывая основные патогенетические аспекты развития мигрени, разработаны ведущие направления в ее лечении. Больные, страдающие тяжелыми или частыми приступами мигрени, являются кандидатами для профилактической терапии, особенно если неотложная терапия неэффективна или плохо переносится пациентом.

Насколько точно врач определит значение ГБ, характер патологического процесса, лежащих в ее основе - зависит своевременность диагностических и лечебных мероприятий и соответственно возможность наиболее благоприятного клинического, социального прогноза.

Коценко Ю.И., Статинова Е.А., Бубликова А.М., Максименко О.Л.

ГОО ВПО «Донецкий национальный медицинский университет имени М. Горького», Донецк

СОВРЕМЕННЫЕ ЛЕЧЕБНО-ДИАГНОСТИЧЕСКИЕ ОСОБЕННОСТИ ПЕРВИЧНЫХ ЦЕФАЛГИЙ ПО НОВОЙ МЕЖДУНАРОДНОЙ КЛАССИФИКАЦИИ ГОЛОВНОЙ БОЛИ - ТРЕТЬЯ РЕДАКЦИЯ (2018)

В данной статье рассмотрены основные изменения, внесенные в обновленную международную классификацию головной боли третьего пересмотра (МКГБ-3, 2018). Определены актуальные лечебнодиагностические направления цефалгий с учетом па- тогенетических механизмов их развития.

Ключевые слова: цефалгия, диагностика, лечение, международная классификация головной боли - 3-я редакция.

Kotsenko Yu.I., Statinova E.A., Bublikova A.M., Maksimenko O.L.

SEI HPE «M. Gorky Donetsk National Medical University», Donetsk

MODERN MEDICAL DIAGNOSTIC FEATURES OF PRIMARY CEPHALGIAS

IN THE NEW INTERNATIONAL CLASSIFICATION OF HEADACHE DISORDERS - THIRD EDITION (2018)

This article discusses the main changes made to the updated international classification of headache disorders of the third edition (ICHD-3, 2018). The actual medical and diagnostic directions of cephalgias are deter- mined taking into account the pathogenetic mechanisms of their development.

Key words: cephalgia, diagnosis, treatment, international classification of headache disorders - 3rd edition. 


\section{ЛИТЕРАТУРА}

1. Осипова В.В. Первичные головные боли: диагностика и лечение. Методические рекомендации. М.; 2017. 27.

2. Шнайдер Н.А., Кондратьев А.В., Шнайдер Н.А., Шульмин А.В. Эпидемиология головных болей. Современные проблемы науки и образования. 2015; 6. URL: http://science-education.ru/ru/article/view?id=22811 (дата обращения: 11.11.2019).

3. American Headache Society (2019) The American Headache Society Position Statement On Integrating New Migraine Treatments Into Clinical Practice. Headache. 2019; 59(1): $1-18$

4. Headache Clasification Subcommittee of the IHS. The International Classification of Headache Disorders, 3rd edition. Cephalalgia 2018; 38(1):1-211.

5. Колбин А.С., Наприенко М.В., Артеменко А.Р., Вилюм И.А., Латышева Н.В., Проскурин М.А., Балыкина Ю.Е. Социально-экономическое бремя хронической мигрени в России. Качественная клиническая практика. 2018; 3: 26-44. DOI: 10.24411/2588-0519-2018-10049.

6. Mia Nielsen, Louise Ninett Carlsen, Signe Bruun Munksgaard, Ida Maria Storm Engelstoft, Rigmor Højland Jensen, Lars Bendtsen. Complete withdrawal is the most effective approach to reduce disability in patients with medication-overuse headache: A randomized controlled open-label trial. Cephalalgia. 2019; 39(7): 863-72.

7. Осипова В.В., Табеева Г.Р. Первичные головные боли: диагностика, клиника, терапия: Практическое руководство. М.: Медицинское информационное агентство; 2014. 336.

8. Гиниатуллин Р.А. Нейрофизиологические механизмы мигрени и новые принципы патогенетического лечения. Казанский медицинский журнал. 2011; 92 (5): 728735.

9. Goadsby P.J., Holland P.R., Martins-Oliveira M., Hoffmann J., Schankin C., Akerman S. Pathophysiology of Migraine - a disorder of sensory processing. Comprehensive review of migraine pathophysiology. Physiol Rev. 2017; 97: 553622 .

10. Pietrobon D., Moskowitz M.A. Pathophysiology of migraine. Annu Rev Physiol. 2013; 75: 365-91.

11. Филатова Е.Г., Амелин А.В., Табеева Г.P. Ready - первое российское мультицентровое исследование эффективности препарата релпакс (элетриптан) при лечении мигрени. Лечение нервных болезней. 2006; 2: 19-22.

12. Hershey A.D. CGRP - the next frontier formigraine. N Engl J Med. 2017; 377(22): 2190-91. doi: 10.1056/ NEJMe1712559.

13. Hougaard A., Hauge A., Guo S., Tfelt-Hansen P. The nitric oxide synthase inhibitor and serotonin-receptor agonist NXN-188 during the aura phase of migraine with aura: a randomized, double-blind, placebo-controlled cross-over study. Scan J Pain. 2012; 4: 48-52.

14. Тадтаева 3. Г. Генетика мигрени. Вестник СанктПетербургского университета. 2013: 1: 70-80.

15. Кондратьева Н.С. Поиск молекулярно-генетических основ патогенеза мигрени: дис. Москва; 2016. 167.

16. Строгонова В. В., Мальцева А. С. Генетические предикторы мигрени. The Journal of scientific articles "Health and Education Millennium”. 2017; 19 (3): 105-107.

17. Osipova V., Jensen R., Tassorelli C. The use of diaries in the management of headache. Handbook of Headache (Practical Management). Eds. P. Martelletti, T.J. Steiner. 2011; 4: 197-209.

18. Alder announces eptinezumab significantly reduces migraine risk meets primary and all key secondary endpoints in pivotal PROMISE 2 phase 3 trial for chronic migraine prevention [news release]. Bothell, WA: Globe Newswire/ Alder BioPharmaceuticals Inc. January 8, 2018. globenewswire.com/news-release/2018/01/08/1284947/0/en/Alder-Announces-Eptinezumab-Significantly-Reduces-Migraine-Risk-Meets-Primary-and-All-Key-Secondary-Endpoints-in-Pivotal-PROMISE-2-Phase-3-Trial-for-Chronic-Migraine-Prevention.html. Accessed April 10, 2018.

\section{REFERENCES}

1. Osipova V.V. Pervichnye golovnye boli: diagnostika i lechenie. Metodicheskie rekomendacii [Primary headaches: diagnostic and treatment. Methodological guidelines]. Moskva. 2017. 27 (in Russian).

2. SHnajder N.A., Kondrat'ev A.V., SHnajder N.A., SHul'min A.V. Epidemiologiya golovnyh bolej [Epidemiology headache]. Sovremennye problemy nauki i obrazovaniya. 2015 ; 6. URL: http://science-education.ru/ru/article/ view?id=22811 (Accessed: 11 Nov 2019). (in Russian).

3. American Headache Society (2019) The American Headache Society Position Statement On Integrating New Migraine Treatments Into Clinical Practice. Headache. 2019; 59(1): $1-18$.

4. Headache Clasification Subcommittee of the IHS. The International Classification of Headache Disorders, 3rd edition. Cephalalgia 2018; 38(1): 1-211..

5. Kolbin A.S., Naprienko M.V., Artemenko A.R., Vilyum I.A., Latysheva N.V., Proskurin M.A., Balykina Yu.Ye. Social'noekonomicheskoe bremya hronicheskoj migreni v Rossii [Socio-economic burden of chronic migraine in Russia]. Kachestvennaya klinicheskaya praktika. 2018; 3: 26-44 (in Russian).

6. Mia Nielsen, Louise Ninett Carlsen, Signe Bruun Munksgaard, Ida Maria Storm Engelstoft, Rigmor Højland Jensen, Lars Bendtsen. Complete withdrawal is the most effective approach to reduce disability in patients with medication-overuse headache: A randomized controlled open-label trial. Cephalalgia. 2019; 39(7): 863-72.

7. Osipova V.V, Tabeeva G.R. Pervichnye golovnye boli: diagnostika, klinika, terapija: Prakticheskoe rukovodstvo. [Primary headaches: diagnostic, clinic and treatment. Practice guidelines] M.: Medicinskoe informacionnoe agentstvo, 2014; 336 (in Russian).

8. Giniatullin R.A. Nejrofiziologicheskie mekhanizmy migreni i novye principy patogeneticheskogo lecheniya [Neurophysiological mechanisms of migraine and new principles of pathogenetic treatment]. Kazan Medical Journal 2011; 92(5): 728-35 (in Russian).

9. Goadsby P.J., Holland P.R., Martins-Oliveira M, Hoffmann J, Schankin C, Akerman S. Pathophysiology of Migraine-a disorder of sensory processing. Comprehensive review of migraine pathophysiology. Physiol Rev. 2017; 97: 553-622.

10. Pietrobon D., Moskowitz M.A. Pathophysiology of migraine. Annu Rev Physiol. 2013; 75: 365-91.

11. Filatova E.G., Amelin A.V., Tabeeva G.R. i dr. Ready - pervoe rossijskoe mul'ticentrovoe issledovanie effektivnosti preparata relpaks (jeletriptan) pri lechenii migreni [Ready is the first Russian multicenter study of the effectiveness of the drug relpax (eletriptan) in the treatment of migraine] Lechenie nervnyh boleznej. 2006; 2: 19-22 (in Russian).

12. Hershey AD. CGRP - the next frontier formigraine. // N Engl J Med. 2017; 377(22): 2190-91. doi: 10.1056/ NEJMe1712559.

13. Hougaard A., Hauge A., Guo S., Tfelt-Hansen P. The nitric oxide synthase inhibitor and serotonin-receptor agonist NXN-188 during the aura phase of migraine with aura: a randomized, double-blind, placebo-controlled cross-over study. Scan J Pain. 2012; 4: 48-52.

14. Tadtaeva Z.G. Genetika migreni [Migraine genetics]. Bulletin of St. Petersburg State University, Ser. 2013; 1 (1): 7080 (in Russian).

15. Kondratieva N.S. Poisk molekulyarno-geneticheskih osnov patogeneza migreni. dis. ... kand.med.nauk [Search molecular-genetic basis of pathogenesis of migraine: Cand.med.sci.diss.abs.]. Moscow; 2016. 167 (in Russian).

16. Strogonova V.V., Maltseva A.S. Geneticheskie prediktory migreni. [Genetic predictors of migraine]. The Journal of scientific articles "Health and Education Millennium". 2017; 19 (3): 105-7 (in Russian).

17. Osipova V., Jensen R., Tassorelli C. The use of diaries in the management of headache. Handbook of Headache (Practical Management). Eds. P. Martelletti, T.J. Steiner. 2011; 4: 197-209.

18. Alder announces eptinezumab significantly reduces migraine risk meets primary and all key secondary endpoints in pivotal PROMISE 2 phase 3 trial for chronic migraine prevention [news release]. Bothell, WA: Globe Newswire/ Alder BioPharmaceuticals Inc. January 8, 2018. globenews- 
19. Азимова Ю.Э., Рачин А.П., Ищенко К.А., Данилов А.Б. Инновационные методы лечения мигрени. РМЖ. Болевой синдром. 2015; 27-30.

20. Dodick D.W., Goadsby P.J., Spierings E.L.H., Scherer J.C., Sweeney S.P., Grayzel D.S. CGRP monoclonal antibody LY2951742 for the prevention of migraine: a phase 2, randomized, double-blind, placebo-controlled study. Lancet Neurol. 2014;13: 885-92.

21. Russell FA, King R, Smillie SJ, Kodji X, Brain SD. Calcitonin gene-related peptide: physiology and pathophysiology. Physiol Rev. 2014; 94 (4): 1099-142.

22. MaassenVan Den Brink A., Meijer J., Villalon C.M., Ferrari M.D. Wiping out CGRP: potential cardiovascular risks. Summary of cardiovascular and cerebrovascular effects of CGRP. Trends Pharmacol Sci. 2016; 37(9): 779-88.

23. Edvinsson L. Clinical data on the CGRP antagonist BIBN4096BS for treatment of migraine attacks. CNS Drug Rev. 2005;11 (1): 69-76.

24. Voss T., Lipton R.B., Dodick D.W., Dupre N., Ge J.Y., Bachman R., et al. A phase IIb randomized, double-blind, placebo-controlled trial of ubrogepant for the acute treatment of migraine. Cephalalgia. 2016; 36: 887-98.

25. Ho TW, Connor KM, Zhang Y, Pearlman E, Koppenhaver J, Fan X, et al. Randomized controlled trial of the CGRP receptor antagonist telcagepant for migraine prevention. Neurology (Minneap). 2014; 83: 958-66.

26. Sun H, Dodick DW, Silberstein S, Goadsby PJ, Reuter U, Ashina $\mathrm{M}$, et al. A randomised, double-blind, placebo-controlled, phase 2 study to evaluate the efficacy and safety of AMG 334 for the prevention of episodic migraine. Lancet Neurol. 2016; 15: 382-90.

27. Goadsby P.J., Reuter U., Hallström Y., et al. A controlled trial of erenumab for episodic migraine. N Engl J Med. 2017; 377 (22): 2123-32. doi: 10.1056/NEJMoa1705848.

28. Lipton R.B., Brennan A., Palmer S., et al. Estimating the clinical effectiveness and value-based price range of erenumab for the prevention of migraine in patients with prior treatment failures: a US societal perspective. I Med Econ. 2018; 3:1-26. doi: 10.1080/13696998.2018.1457533.

29. Головачева В.А., Парфенов В.А. Когнитивно-поведенческая терапия в лечении пациентов с мигренью. Невролог. журн. 2015; 3(20): 37-43

30. Hepp Z., Dodick D.W., Varon S.F., Gillard P., Hansen R.N., Devine E.B. Adherence to oral migraine-preventive medications among patients with chronic migraine. Cephalalgia. $2015 ; 35(6)$ : 478-88.

31. Zhu S., Marmura M.J. Non-Invasive Neuromodulation for Headache Disorders // Current Neurology Neuroscience Reports. 2016. 16(2): 11.

32. Becker W.J. Acute Migraine Treatment in Adults. Headache. 2015 ; 55: 778-93.

33. Wrobel Goldberg S., Silberstein S.D. Targeting CGRP: A New Era for Migraine Treatment. CNS Drugs. 2015; 29 (6): 443-52.

34. Tso AR, Goadsby PJ. Anti-CGRP monoclonal antibodies: the next era of migraine prevention? Curr Treat Options Neurol. 2017;19(8): 27. ncbi.nlm.nih.gov/pmc/articles/PMC5486583.

35. Dominquez C, et al. OnabotulinumtoxinA in chronic migraine: predictors of response. A prospective multicentre descriptive study. Eur J Neurol. 2018; 25(2): 411-16. DOI: 10.1111/ene.13523

36. Bigal M.E., Dodick D.W., Krymchantowski A.V., Vander Pluym J.H., Tepper S.J., Aycardi E., et al. TEV-48125 for the preventive treatment of chronic migraine-efficacy at early time points. Neurology (Minneap). 2016; 87: 41-8.

37. Bigal M.E., Dodick D.W., Rapoport AM, Silberstein SD, Ma Y, Yang R, et al. Safety, tolerability, and efficacy of TEV48125 for preventive treatment of high-frequency episodic migraine: a multicentre, randomized, double-blind, placebo-controlled, phase 2b study. Lancet Neurol. 2015; 14 : 1081-90.

38. Bigal M.E., Edvinsson L., Rapoport A.M., Lipton R.B., Spierings E.L.H., Diener H. C., et al. Safety, tolerability, and efficacy of TEV-48125 for preventive treatment of chronic migraine: a multicentre, randomized, double-blind, pla-
wire.com/news-release/2018/01/08/1284947/0/en/Alder-Announces-Eptinezumab-Significantly-Reduces-Migraine-Risk-Meets-Primary-and-All-Key-Secondary-Endpoints-in-Pivotal-PROMISE-2-Phase-3-Trial-for-Chronic-Migraine-Prevention.html. Accessed April 10, 2018.

19. Azimova YU.E., Rachin A.P., Ishchenko K.A., Danilov A.B. Innovacionnye metody lecheniya migreni. [Innovative treatments for migraine.]. RMJ. Bolevoj sindrom. 2015; 27-30. (in Russian).

20. Dodick D.W., Goadsby P.J., Spierings E.L.H., Scherer J.C., Sweeney S.P., Grayzel D.S. CGRP monoclonal antibody LY2951742 for the prevention of migraine: a phase 2, randomized, double-blind, placebo-controlled study. Lancet Neurol. 2014;13: 885-92.

21. Russell F.A., King R., Smillie S.J., Kodji X., Brain S.D. Calcitonin gene-related peptide: physiology and pathophysiology. Physiol Rev. 2014; 94(4): 1099-142.

22. MaassenVan Den Brink A., Meijer J, Villalon CM, Ferrari MD. Wiping out CGRP: potential cardiovascular risks. Summary of cardiovascular and cerebrovascular effects of CGRP. Trends Pharmacol Sci. 2016; 37(9): 779-88.

23. Edvinsson L. Clinical data on the CGRP antagonist BIBN4096BS for treatment of migraine attacks. CNS Drug Rev. 2005; 11 (1): 69-76.

24. Voss T., Lipton R.B., Dodick D.W., Dupre N., Ge J.Y., Bachman R., et al. A phase IIb randomized, double-blind, placebo-controlled trial of ubrogepant for the acute treatment of migraine. Cephalalgia. 2016; 36: 887-98.

25. Ho T.W., Connor K.M., Zhang Y., Pearlman E., Koppenhaver J., Fan X., et al. Randomized controlled trial of the CGRP receptor antagonist telcagepant for migraine prevention. Neurology (Minneap). 2014; 83: 958-66.

26. Sun H, Dodick D.W., Silberstein S., Goadsby P.J., Reuter U., Ashina M., et al. A randomised, double-blind, placebo-controlled, phase 2 study to evaluate the efficacy and safety of AMG 334 for the prevention of episodic migraine. Lancet Neurol. 2016; 15: 382-90.

27. Goadsby P.J., Reuter U., Hallström Y., et al. A controlled trial of erenumab for episodic migraine. N Engl J Med. 2017;377(22):2123-2132. DOI: 10.1056/NEJMoa1705848.

28. Lipton R.B., Brennan A., Palmer S., et al. Estimating the clinical effectiveness and value-based price range of erenumab for the prevention of migraine in patients with prior treatment failures: a US societal perspective. J Med Econ. 2018; 3:1-26. DOI: 10.1080/13696998.2018.1457533.

29. Golovacheva V.A., Parfenov V.A. Kognitivno-povedencheskaja terapija v lechenii pacientov s migren'ju. [Cognitive-behavioral therapy in the treatment of patients with migraine.]. Nevrologicheskij zhurnal. 2015; 3(20): 37-43 (in Russian).

30. Hepp Z., Dodick D.W., Varon S.F., Gillard P., Hansen R.N., Devine E.B.. Adherence to oral migraine-preventive medications among patients with chronic migraine. Cephalalgia. 2015; 35(6): 478-88.

31. Zhu S., Marmura M.J. Non-Invasive Neuromodulation for Headache Disorders. Current Neurology Neuroscience Reports. 2016: 16(2): 11 .

32. Becker W.J. Acute Migraine Treatment in Adults. Headache. 2015; 55: 778-93.

33. Wrobel Goldberg S., Silberstein S.D. Targeting CGRP: A New Era for Migraine Treatment. CNS Drugs. 2015; 29 (6): 443-52.

34. Tso AR, Goadsby PI. Anti-CGRP monoclonal antibodies: the next era of migraine prevention? Curr Treat Options Neurol. 2017; 19(8): 27. URL: ncbi.nlm.nih.gov/pmc/articles/PMC5486583. (Accessed April 2, 2018).

35. Dominquez C, et al. Onabotulinumtoxin A in chronic migraine: predictors of response. A prospective multicentre descriptive study. Eur J Neurol. 2018; 25(2): 411-416. DOI: 10.1111/ene.13523.

36. Bigal M.E., Dodick D.W., Krymchantowski A.V., Vander Pluym J.H., Tepper S.J., Aycardi E., et al. TEV-48125 for the preventive treatment of chronic migraine-efficacy at early time points. Neurology (Minneap). 2016; 87: 41-8.

37. Bigal M.E., Dodick D.W., Rapoport A.M., Silberstein S.D., Ma Y., Yang R., et al. Safety, tolerability, and efficacy of TEV-48125 for preventive treatment of high-frequency episodic migraine: a multicentre, randomized, doubleblind, placebo-controlled, phase $2 \mathrm{~b}$ study. Lancet Neurol. 2015; 14: 1081-90. 
cebo-controlled, phase 2b study. Lancet Neurol. 2015; 14: 1091-100.

39. Silberstein S.D., Dodick D.W., Bigal M.E., et al. Fremanezumab for the preventive treatment ofchronic migraine. N Engl J Med. 2017; 377(22): 2113-22. doi: 10.1056/NEJMoa1709038.

40. Sklijarevski V., Oakes T.M., Zhan Q., et al. Effect of different doses of galcanezumab vs placebo for episodic migraine prevention: a randomized clinical trial. JAMA Neurol. 2018; 75(2): 187-93. doi: 10.1001/jamaneurol.2017.3859.

41. Lilly's galcanezumab significantly reduces number of migraine headache days for patients with migraine: new results presented at AHS [news release]. Indianapolis, IN: PRNewswire/Eli Lilly and Co; June 10, 2017. URL: prnewswire.com/news-releases/lillys-galcanezumab-significantly-reduces-number-of-migraine-headache-days-for-patients-with-migraine-new-results-presented-at-ahs300471742.html. (Accessed April 10, 2018).

42. Buse DC, Lipton RB, Hallström Y, Reuter U, Tepper SI, Zhang F, Sapra S, Picard H, Mikol DD, Lenz RA. Migrainerelated disability, impact, and health-related quality of life among patients with episodic migraine receiving preventive treatment with erenumab. Cephalalgia. 2018; 38(10): 1622-31. doi: 10.1177/0333102418789072.

43. Goadsby PI, Reuter U, Hallström Y, Broessner G, Bonner JH, Zhang F, Sapra S, Picard H, Mikol DD, Lenz RA. A Controlled Trial of Erenumab for Episodic Migraine. N Engl J Med. 2017; 377(22): 2123-32. doi: 10.1056/NEJMoa1705848.

44. Sunfa Cheng, Herman Picard, Feng Zhang, Osa Eisele, Daniel Mikol. Efficacy and safety of erenumab for migraine prevention: an overview. Japanese Journal of Headache. 2019; 45(3): 493-505.

45. Pellesi L., Guerzoni S., Pini L.A. Spotlight on anti-CGRP monoclonal antibodies in migraine: the clinical evidence to date. Clin Pharmacol Drug Dev. 2017; 6(6): 534-47. doi: 10.1002/cpdd.345.

46. Edvinsson L. CGRP receptor antagonists and antibodies against CGRP and its receptor in migraine treatment. Comprehensive review of CGRP pharmacology. Br J Clin Pharmacol. 2015; 80:193-9.

47. Färkkilä M., Diener H.C., Géraud G. et al. and the COL MIG-202 study group. Efficacy and tolerability of lasmiditan, an oral $5-\mathrm{HT}(1 \mathrm{~F})$ receptor agonist, for the acute treatment of migraine: a phase 2 randomised, placebo-controlled, parallel-group, dose-ranging study // Lancet Neurol. 2012; 11: 405-13.

48. Ferrari M.D., Färkkilä M., Reuter U. et al. and the European COL-144 Investigators. Acute treatment of migraine with the selective 5-HT1F receptor agonist lasmiditan-a randomised proof-of-concept trial. Cephalalgia. 2010; 30: $1170-8$.

49. Gomez-Mancilla B., Brand R., Jürgens T.P. et al. and the BGG492 Study Group. Randomized, multicenter trial to assess the efficacy, safety and tolerability of a single dose of a novel AMPA receptor antagonist BGG492 for the treatment of acute migraine attacks. Cephalalgia. 2014; 34 : 103-113.

50. Chizh B.A., O’Donnell M.B., Napolitano A. et al. The effects of the TRPV1 antagonist SB-705498 on TRPV1 receptor-mediated activity and inflammatory hyperalgesia in humans. Pain. 2007; 132: 132-141.

51. Agneta Snoer, Anne Luise H. Vollesen, Rasmus P. Beske, Song Guo, Jan Hoffmann,Jan Fahrenkrug, Niklas Rye Jørgensen, Torben Martinussen, Rigmor H Jensen, Messoud Ashina. Calcitonin-gene related peptide and disease activity in cluster headache. Cephalalgia. 2019; 39(5): 575-84.

52. Pernille Linde Jellestad, Louise Ninett Carlsen, Maria Lurenda Westergaard, Signe Bruun Munksgaard, Lars Bendtsen, Miguel Lainez, Ricardo Fadic, Zaza Katsarava, Maria Teresa Goicochea, Santiago Spadafora, Rigmor Højland Jensen, Giuseppe Nappi, Cristina Tassorelli. Economic benefits of treating medication-overuse headache - results from the multicenter COMOESTAS project. Cephalalgia. 2019; 39(2):274-85.
38. Bigal M.E., Edvinsson L., Rapoport A.M., Lipton R.B. Spierings E.L.H., Diener H.-C., et al. Safety, tolerability, and efficacy of TEV-48125 for preventive treatment of chronic migraine: a multicentre, randomized, doubleblind, placebo-controlled, phase $2 \mathrm{~b}$ study. Lancet Neurol. 2015; 14: 1091-100.

39. Silberstein S.D., Dodick D.W., Bigal M.E., et al. Fremanezumab for the preventive treatment ofchronic migraine. $\mathrm{N}$ Engl J Med. 2017; 377(22): 2113-2122. DOI: 10.1056/NEJMoa1709038.

40. Sklijarevski V., Oakes T.M., Zhan Q., et al. Effect of different doses of galcanezumab vs placebo for episodic migraine prevention: a randomized clinical trial. JAMA Neurol. 2018; 75(2): 187-93. DOI: 10.1001/jamaneurol.2017.3859.

41. Lilly's galcanezumab significantly reduces number of migraine headache days for patients with migraine: new results presented at AHS [news release]. Indianapolis, IN: PRNewswire/Eli Lilly and Co; June 10, 2017. prnewswire. com/news-releases/lillys-galcanezumab-significantly-reduces-number-of-migraine-headache-days-for-patientswith-migraine-new-results-presented-at-ahs-300471742. html (Accessed April 10, 2018).

42. Buse D.C., Lipton R.B., Hallström Y., Reuter U., Tepper S.J., Zhang F., Sapra S., Picard H., Mikol D.D., Lenz R.A Migraine-related disability, impact, and health-related quality of life among patients with episodic migraine receiving preventive treatment with erenumab. Cephalalgia. 2018; 38(10): 1622-31. DOI: 10.1177/0333102418789072.

43. Goadsby PI, Reuter U, Hallström Y, Broessner G, Bonner JH, Zhang F, Sapra S, Picard H, Mikol DD, Lenz RA. A Controlled Trial of Erenumab for Episodic Migraine. N Engl J Med. 2017; 377(22): 2123-32. DOI: 10.1056/NEJMoa1705848.

44. Sunfa Cheng, Herman Picard, Feng Zhang, Osa Eisele, Daniel Mikol. Efficacy and safety of erenumab for migraine prevention: an overview. Japanese Journal of Headache. 2019: 45(3): 493-505.

45. Pellesi L., Guerzoni S., Pini L.A. Spotlight on anti-CGRP monoclonal antibodies in migraine: the clinical evidence to date. Clin Pharmacol Drug Dev. 2017; 6(6): 534-47. DOI: 10.1002/cpdd.345.

46. Edvinsson L. CGRP receptor antagonists and antibodies against CGRP and its receptor in migraine treatment. Comprehensive review of CGRP pharmacology. Br J Clin Pharmacol. 2015; 80:193-9.

47. Färkkilä M., Diener H.C., Géraud G. et al. and the COL MIG-202 study group. Efficacy and tolerability of lasmiditan, an oral $5-\mathrm{HT}(1 \mathrm{~F})$ receptor agonist, for the acute treatment of migraine: a phase 2 randomised, placebo-controlled, parallel-group, dose-ranging study // Lancet Neurol. 2012; 11: 405-13.

48. Ferrari M.D., Färkkilä M., Reuter U. et al. and the European COL-144 Investigators. Acute treatment of migraine with the selective 5-HT1F receptor agonist lasmiditan-a randomised proof-of-concept trial. Cephalalgia. 2010; 30: 1170-8.

49. Gomez-Mancilla B., Brand R., Jürgens T.P. et al. and the BGG492 Study Group. Randomized, multicenter trial to assess the efficacy, safety and tolerability of a single dose of a novel AMPA receptor antagonist BGG492 for the treatment of acute migraine attacks. Cephalalgia. 2014; 34. 103-13.

50. Chizh B.A., O’Donnell M.B., Napolitano A. et al. The effects of the TRPV1 antagonist SB-705498 on TRPV1 receptor-mediated activity and inflammatory hyperalgesia in humans. Pain. 2007; 132: 132-41.

51. Agneta Snoer, Anne Luise H Vollesen, Rasmus P Beske, Song Guo, Jan Hoffmann, Jan Fahrenkrug, Niklas Rye Jørgensen, Torben Martinussen, Rigmor H Jensen, Messoud Ashina. Calcitonin-gene related peptide and disease activity in cluster headache. Cephalalgia. 2019; 39(5): 575-84.

52. Pernille Linde Jellestad, Louise Ninett Carlsen, Maria Lurenda Westergaard, Signe Bruun Munksgaard, Lars Bendtsen, Miguel Lainez, Ricardo Fadic, Zaza Katsarava, Maria Teresa Goicochea, Santiago Spadafora, Rigmor Højland Jensen, Giuseppe Nappi, Cristina Tassorelli. Economic benefits of treating medication-overuse headache - results from the multicenter COMOESTAS project. Cephalalgia. 2019; 39(2):274-85. 